\title{
Endoscopic-Assisted Transaxillary Approach for First Rib Resection in Thoracic Outlet Syndrome
}

\author{
Kozo Furushima, M.D., Tadanao Funakoshi, M.D., Hiroshi Kusano, M.D., \\ Azusa Miyamoto, M.S., Toru Takahashi, M.D., Yukio Horiuchi, M.D., and \\ Yoshiyasu Itoh, M.D.
}

\begin{abstract}
Purpose: To assess the feasibility, safety, and clinical outcomes of an endoscopic-assisted transaxillary approach of first rib resection for thoracic outlet syndrome (TOS) and to compare the differences in demographic and clinical data between satisfactory and unsatisfactory outcomes using this approach. Methods: We retrospectively identified patients who underwent endoscopic-assisted first rib partial resection. A transaxillary approach for the first rib resection and neurovascular decompression were undertaken under magnified visualization. Endoscopic classification of neurovascular bundle (NVB) patterns and interscalene distance (ISD) between anterior and middle scalene muscles were evaluated intraoperatively. We assessed the Roos and DASH scores. Results: We reviewed 131 cases of TOS (48 women and 83 men; mean age 26.2 years; range 12 to 57). Roos classification revealed $80.2 \%$ excellent or good results. DASH scores improved significantly from $40.7 \pm 20.0$ to $15.7 \pm 19.6(P<.001)$. The complication rate was low $(5.3 \%)$, with 4 pneumothorax and 3 other complications. Intraoperative NVB classification revealed 30 cases of parallel type, in which the artery and nerve travel in parallel; 69 oblique types, and 30 vertical types, in which the nerve was completely behind the middle scalene muscle or abnormal band. The ISD was narrower $(5.4 \pm 3.6 \mathrm{~mm})$ than in previous cadaveric studies. The ISD in the parallel patterns was wider than that in the vertical patterns. In the satisfactory group, we found a significantly larger number of men, younger patients, athletes, and patients with a lower preoperative DASH score. Conclusions: An endoscopic-assisted transaxillary approach for first rib resection in TOS provides an excellent magnified visualization, safely allowing sufficient decompression of the neurovascular bundle and satisfactory surgical outcomes. Younger male athletes with TOS may be better candidates for this procedure. Level of Evidence: IV, therapeutic case series.
\end{abstract}

$\mathbf{T}$ horacic outlet syndrome (TOS) is a complex disorder of signs and symptoms resulting from compression of the brachial plexus and subclavian vessels supplying the upper limb. ${ }^{1-7}$ Although TOS is a well-described disorder, it is incompletely understood, difficult to diagnose, and often poorly managed. Roos ${ }^{8}$ reported that TOS is underdiagnosed. A later article reported that physicians who do not regularly treat patients with TOS might not have an accurate view of this disorder, its treatment, or the possible success rate

From Keiyu Orthopaedic Hospital, Tatebayashi, Japan.

The authors report that they have no conflicts of interest in the authorship and publication of this article. Full ICMJE author disclosure forms are available for this article online, as supplementary material.

Received March 22, 2020; accepted August 31, 2020.

Address correspondence to Tadanao Funakoshi, Keiyu Orthopaedic Hospital, 2267 Akoda, Tatebayashi, Japan.E-mail:tfunakoshi@gmail.com

(C) 2020 THE AUTHORS. Published by Elsevier Inc. on behalf of the Arthroscopy Association of North America. This is an open access article under the CC BY-NC-ND license (http://creativecommons.org/licenses/by-nc-nd/4.0/). 2666-061X/20344

https://doi.org/10.1016/j.asmr.2020.08.019 of treatment. ${ }^{9}$ It has also been proposed that orthopedists who usually see patients with disorders of the upper extremities should consider the possibility of a diagnosis of TOS. ${ }^{10}$ Accurately diagnosing TOS is challenging, since it has varied symptoms and atypical radiographic findings, which may lead to less objective diagnostic criteria being applied.

Both nonsurgical and surgical management for TOS remain challenging. Transaxillary first rib resection is a well-established surgical treatment for patients with symptomatic TOS. ${ }^{1,11-14}$ The transaxillary approach provides good exposure of the anterior and lateral part of the first rib, with an excellent cosmetic result. However, this approach sometimes does not allow adequate exposure of the insertion point of the middle scalene muscle to the posterior part of the first rib and proximal neurovascular bundle. Because surgery for TOS involves many complex and intimately related structures, possible complications are numerous and may be severe. ${ }^{9}$ Reported complications include brachial plexus dysfunction and fatal subclavian artery or vein injury. ${ }^{14-16}$ 
Recent articles have shown that with the help of an endoscope, safer and less invasive surgery has been achieved. ${ }^{17-21}$ In addition, endoscopic-assisted surgery provides excellent visualization of the thoracic outlet. We considered that endoscopic intraoperative observations could provide information on the portion, degree, and pattern of neurovascular entrapment in the thoracic outlet. Peek et al. ${ }^{22}$ reported that the surgical treatment of TOS seems to be beneficial in most patients and is relatively safe. However, most articles did not focus on neurolysis for neurological symptoms. The largest challenge remains the diagnosis of TOS, especially neurogenic TOS, because standardized diagnostic criteria are lacking.

The purpose of this study was to assess the feasibility, safety, and clinical outcomes of an endoscopic-assisted transaxillary approach of first rib resection for TOS and to compare the differences in demographic and clinical data between satisfactory and unsatisfactory outcomes using this approach. Our hypothesis was that endoscopic-assisted surgery would provide adequate visualization to identify the specific pathologies that contribute to TOS and to safely achieve sufficient decompression of the neurovascular bundle, and further, that we can identify demographic factors that demonstrate the best outcomes.

\section{Methods}

This study was approved by the institutional review board (3114).

Data from consecutive patients who were treated for TOS between November 2014 and September 2018 in our hospitals were retrospectively reviewed. To be included in this series, patients were followed up for a minimum of 12 months from the time of surgery. Patients with a cervical rib seen on a plain cervical or chest radiograph were included in the analysis. Patients with obvious neurological disease that was related to cervical spondylosis or obvious inflammatory disease and a Pancoast tumor were excluded. Because patients are often seen by multiple physicians, undergo misdiagnosis, or are informed that their condition is psychosomatic, ${ }^{9}$ a psychological diagnosis was not excluded in the current study. This study was approved by the relevant institutional review board. The diagnosis of TOS was based on clinical features, cervical plane radiographs, ultrasonography (US), 3-dimensional computed tomography angiography (3D angiography), and magnetic resonance imaging (MRI).

\section{Diagnosis}

Patients' presenting complaints included neurologic symptoms such as pain, paresthesia, numbness, tingling, motor weakness or dysfunction of the upper extremity, or vascular symptoms such as coldness, easy fatigability, pallor, swelling, discoloration, or a heavy feeling in the upper extremity. The patients with TOS sometimes complained of head and neck symptoms, including headache, dizziness, and tinnitus. The upper extremity could be congested and edematous with venous symptoms and might appear pale with arterial symptoms.

We consider the Wright test ${ }^{23}$ and the Roos test ${ }^{24}$ as the most reliable diagnostic examinations for TOS. The Wright test was originally described as a decrease in the radial pulse with the arm in hyperabduction and externally rotated. The elevated arm stress test by Roos was described as reproduction of symptoms with opening and closing fist in brachium at right angles to the thorax, and the forearm flexed $90^{\circ}$. The Roos test is favored for neurologic symptoms, because this examination may evaluate irritation or compression of the brachial plexus itself, regardless of radial pulse alterations.

Indications for surgery included the failure of $>6$ months of conservative treatment, 3D angiography evidence of artery interruption or decreasing peak systolic velocity of the axially artery with elevated arm position on Doppler US, and $<10-\mathrm{mm}$ narrowing of the interscalene region on US. For conservative treatment, we instructed patients to avoid heavy use of the upper extremity, including sports activity, until symptoms improved. Physical therapy and the gradual incorporation of stretching and strengthening exercises, including improvement of scapulothoracic function and costoclavicular narrowing, were monitored by physical therapists.

\section{Surgical Technique}

\section{Incision and Exposure}

Patients are set up in a lateral decubitus position and under general anesthesia, with local anesthesia. The open surgical technique of transaxillary first rib resection has been described by Roos. ${ }^{1,25,26}$ A 5- to 8-cm incision is made over the third intercostal space at the bottom of the hairline in the midaxillary line between the pectoralis and latissimus dorsi muscles. A $4.0-\mathrm{mm}$ $30^{\circ}$ arthroscope is introduced with an additional small port placed anterior to the latissimus dorsi. Elevation of the axial fat nodes and vessels by a large retractor is critical to open the ceiling of the operative field and maintain viewing and working space.

\section{Identification of Neurovascular Structures and Scalene Muscles}

The first rib may be identified by characteristic flat surface and insertion of the posterior interscalene muscle. The scope allows for visual identification and confirmation of the first rib and the contents of the thoracic outlet (Fig 1). The large fluttering of the subclavian vein or artery in some patients would be good landmarks for identification of the thoracic outlet. 
Fig 1. Endoscopic classification of neurovascular bundle (NVB) patterns was evaluated intraoperatively based on alignment of the nerve, artery, and vein, following 3 types: parallel type, in which the artery and nerve travel parallel (A and D), oblique type, in which the nerves are partially behind the artery (B and $\mathrm{E})$, and vertical type, in which the nerves are totally behind the middle scalene muscle or abnormal band ( $\mathrm{C}$ and $\mathrm{F}$ ). Abbreviations: A, artery; ASM, anterior scalene muscle; MSM, middle scalene muscle; $\mathrm{N}$, nerve; $\mathrm{V}$, vein.
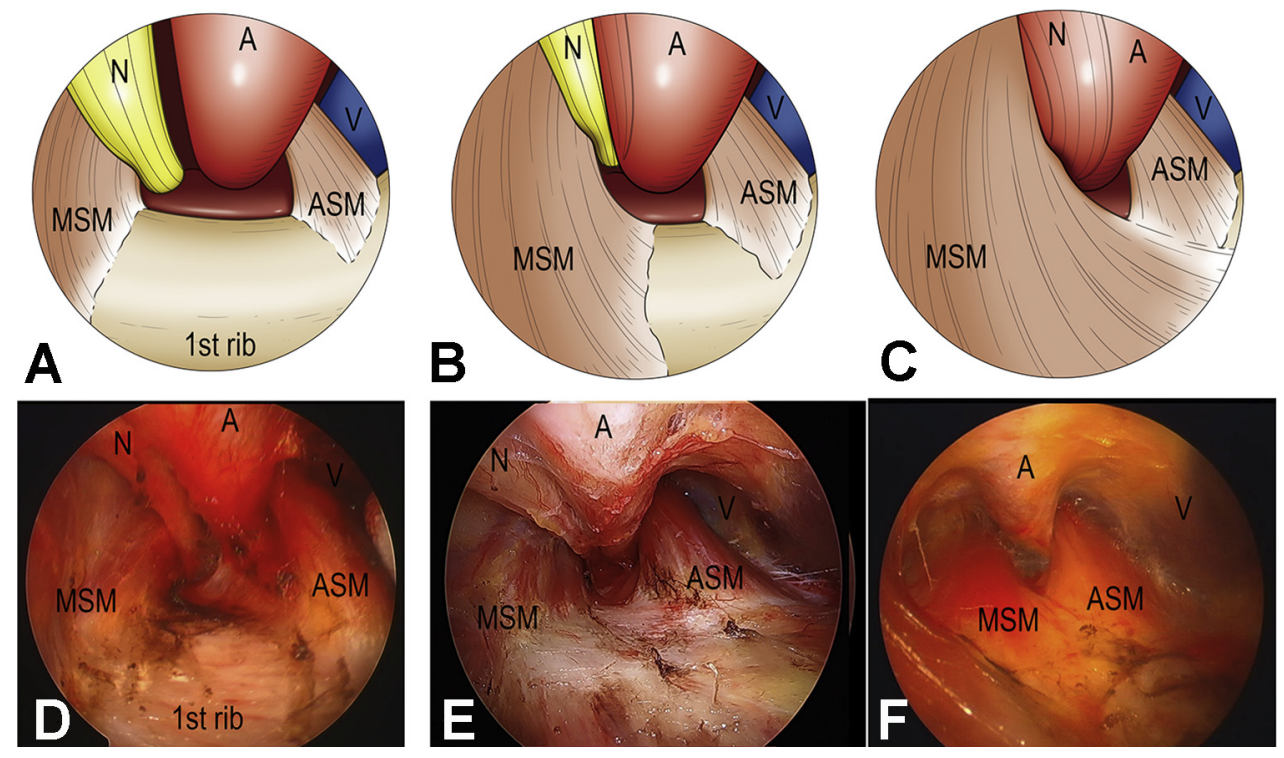

However, these vital structures (the subclavian vein, the subclavian artery, and brachial plexus) are carefully identified. The lung does not need to be collapsed during the procedure. The scalene and serratus anterior muscles' insertion to the first rib must be divided with special care to avoid opening the cupola of the pleura, which rises above the first rib in contact with the medial and lateral surface.

\section{Endoscopic Classification and Interscalene Distance Measurement}

Endoscopic classification of neurovascular bundle (NVB) patterns is evaluated intraoperatively based on alignment of the nerve, artery, and vein, according to 3 types; parallel, in which the artery and nerve travel parallel (Fig 1A, D); oblique, in which the nerves are partially behind the artery (Fig 1B, E); and vertical, in which the nerves are totally behind the middle scalene muscle or abnormal band (Fig 1C, F). In addition, the distance between the anterior and middle scalene muscles at the edge of the first rib is measured as the interscalene distance (ISD) (Fig 2A).

\section{Partial First Rib Resection}

The anterior and middle scalene muscles are dissected free of origin at the first rib and divided under good visualization with great care to avoid injury to the subclavian vein immediately anterior to the anterior scalene muscles. A periosteal elevator or custom ordered elevator (Tanaka Medical Instruments, Tokyo, Japan) is then used to dissect the lateral surface of the rib. The first rib is transected anteriorly near the costochondral junction and posteriorly as close to the transverse process as possible in a piece-by-piece fashion. The endoscope assists in ensuring a safe removal of the first rib from the inside of a rongeur at the transection, especially the posterior part of the first rib (Fig 2B, C, D). We have found that the anterior scalene attaches not only to the first rib but also to the pleura. Therefore, at the release of the anterior scalene muscle insertion, pleural injury must be avoided.

\section{Confirmation of Release of Neurovascular Bundles and Possible Pleura Injury}

After partial resection of the first rib, the release of the neurovascular bundles is confirmed (Fig 2E, F). A congenital fibrous band, usually coming off the tip of a rib or a long C7 transverse process (abortive cervical rib), inserting at the scalene tubercle, must be removed, not merely divided. In addition, release and decompression of the brachial plexus is performed under high magnification. Signs of fibrosis, palpated hardness, or hypertrophic epineural sheath are released to restore softness and ensure enough space between the artery and nerve. Last, the existence is confirmed of abnormal band patterns, as reported by Roos. ${ }^{24}$ No evidence of pseudoneuroma was found in our patients, and no epineuriotomy was performed. The pleura was inspected by endoscopic visualization and by inserting saline into the chest and having the anesthetist overinflate the lungs. If a pneumothorax was found, a chest drain was placed and left in place for 2 days.

\section{Preoperative and Postoperative Clinical Assessment}

Results were assessed according to the classifications of Roos ${ }^{25}$ and Derkash ${ }^{6}$ as follows: excellent: complete relief of symptoms with return to full employment and recreational sports; good: mild residual symptoms 


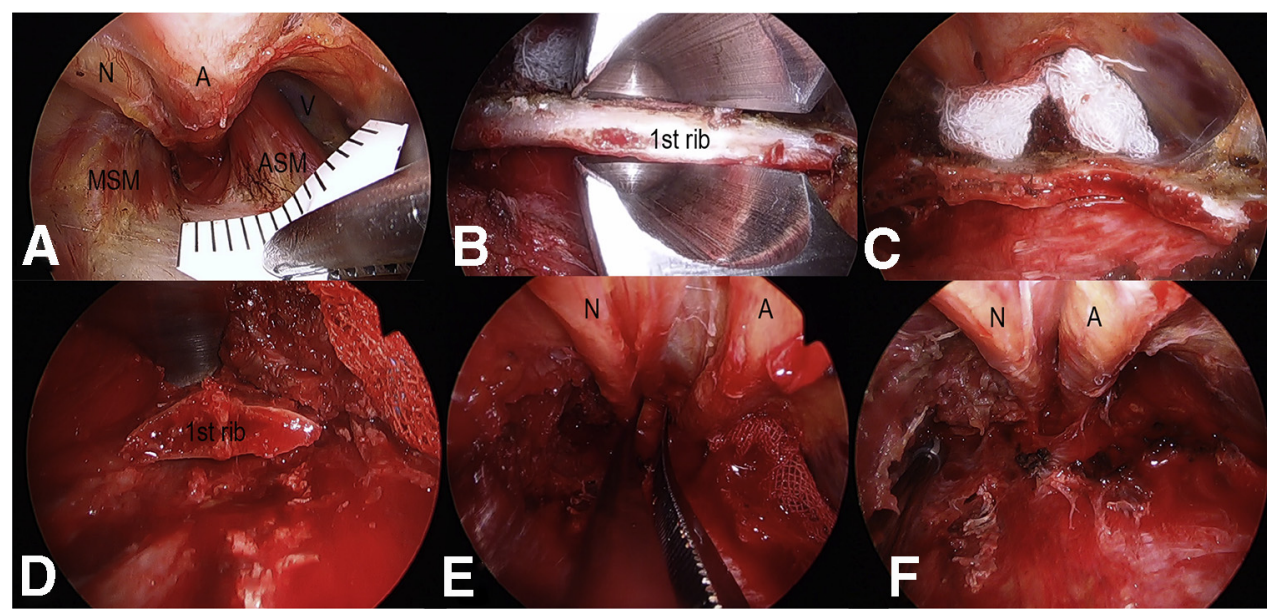

Fig 2. (A) The scope allows for visual identification and confirmation of the first rib and the contents of the thoracic outlet. The distance between the anterior and middle scalene muscles at the edge of the first clavicle was measured as the interscalene distance. (B, C, D) The first rib is transected anteriorly near the costochondral junction and posteriorly as close to the transverse process as possible in a piece-bypiece fashion. The endoscope assist to ensure safe removal of the first rib from the inside of a rongeur at the transection, especially posterior part of the first rib. (E, F) The subclavian vein, artery, and brachial plex nerves were released after first rib resection was relaxed. Anterior and middle scalene muscles were released by scalenectomy. Abbreviations: A, artery; ASM, anterior scalene muscle; MSM, middle scalene muscle; $\mathrm{N}$, nerve; $\mathrm{V}$, vein.

with return to employment and some recreational sports; fair: partial relief of symptoms with return to employment, but restricted to not lift heavy objects above head height; and poor: no improvement (or worsening) of symptoms. The Disability of the Arm, Shoulder, and Hand (DASH) score were used for general clinical outcomes. These clinical evaluations were conducted preoperatively and at final follow-up after surgery. We recorded complications related to the procedures.

\section{Statistical analyses}

Chi-squared test was used to compare the clinical findings preoperatively and at the final follow-up. Wilcoxon signed rank test was used to compare the DASH score recorded preoperatively and at the final follow-up. We divided the postoperative classification into 2 groups: satisfactory, which included the categories excellent and good, and unsatisfactory, which included the fair or poor results. Chi-squared test was used to compare the satisfactory and the unsatisfactory group by sex, dominant limb involvement, sports activity, and pattern of the neurovascular bundle. Mann-Whitney $U$ test was used to compare the satisfactory and unsatisfactory groups for age, height, body weight, body mass index, symptom duration, ISD, and preoperative and the postoperative DASH scores. $P$ values $<.05$ were considered statistically significant.

\section{Results}

During the study period, 445 patients were diagnosed as having TOS, and 159 underwent endoscopic-assisted partial resection of the first rib. Eleven patients were lost to follow-up, 7 had a short follow-up period, and 10 had insufficient images for evaluation, leaving $131 \mathrm{pa}-$ tients (48 women and 83 men; mean age 26.2 years; range 12 to 57 ) whose data could be analyzed (Table 1 ). The average follow-up was 26.3 months (range 12.0 to 55.5).

The findings of neurovascular patterns at surgery were varied (Table 2). Intraoperative findings showed that dense fibrous tissue (spider view), which caused difficulty in visualizing the field immediately before the operation, was found in half of the patients (61 cases). In the endoscopic classification of NVB, 30 cases of parallel type, 69 cases of oblique type, and 30 cases of vertical type were noted. The ISD was small (average $5.4 \mathrm{~mm}$; range 0 to 13) but tended to be wider in the parallel patterns than in the vertical patterns (Table 2). In the current study, abnormal band patterns, as reported by Roos, ${ }^{24}$ were found in $38.2 \%$ of the patients. We found 3 cases of cervical rib (Roos type 1 or 2), 18 cases of fibrous string (Roos 3 or 4), 15 cases of the scalenus minimus muscle (Roos type 5 or 6 ), and 14 cases of other undefined anomalies. Adhesion between the artery and nerves was found in $76 \%$ of patients. Hypertrophy of the anterior or middle scalene muscle was found in $>50 \%$ of patients. The insertion of the 
Table 1. Demographic data $(\mathrm{N}=131)$

\begin{tabular}{lc}
\hline \multicolumn{1}{c}{ Clinical Feature } & Value \\
\hline Sex (women/men) & $48 / 83$ \\
Age at surgery (y) & $26.2 \pm 13.2$ \\
Height (cm) & $166.2 \pm 8.6$ \\
Weight (kg) & $61.4 \pm 11.9$ \\
Dominant/nondominant & $81 / 50$ \\
Follow up duration (mo) & $26.3 \pm 11.0$ \\
Chief complaint & \\
$\quad$ Upper extremity pain & $81(61.8)$ \\
Shoulder pain & $74(56.5)$ \\
Elbow pain & $63(48.1)$ \\
Swelling of the upper extremity & $5(3.8)$ \\
Coldness & $23(17.6)$ \\
Upper extremity numbness & $76(58.0)$ \\
$\quad$ Loss of range of motion & $31(23.7)$ \\
Symptom duration (mo) & $17.6 \pm 30.2$ \\
Abnormal angiography & $58(44.3)$ \\
\hline Values are expressed as n, mean \pm standard deviation, & or $\mathrm{n}(\%)$.
\end{tabular}

anterior or middle scalene exceeded the scalene tubercle and extended onto the superior surface of the rib in half of the patients. Adhesion and hypertrophy were thought to narrow the ISD.

Clinical outcomes of the surgery in all 131 cases are summarized in Table 3. The characteristic clinical findings, including tenderness, neurological symptoms, Wright test, and Roos test, were significantly improved after the operation. The outcomes of the Roos and Derkash classifications revealed $80.2 \%$ excellent or good results. DASH scores improved significantly from 40.7 to 15.7 points $(P<.001)$ (recovery rate was $65.5 \%)$. Eight patients $(6.1 \%)$ reported no significant improvement in their symptoms during the follow-up period. Table 4 shows the comparison of demographic and clinical data between thesatisfactory and not satisfactory groups. In the satisfactory group, we found a significantly larger number of men; the patients were

Table 2. Intraoperative findings

\begin{tabular}{lc}
\hline \multicolumn{1}{c}{ Finding } & Value \\
\hline Dense fibrous tissue (spider view) & $61(46.6)$ \\
NVB (parallel/oblique/vertical) & $30 / 69 / 30$ \\
ISD (mm) & $5.4 \pm 3.6$ \\
ISD in NVB (parallel/oblique/vertical) $(\mathrm{mm})$ & $8.1 / 5.6 / 2.3$ \\
Anomaly & $50(38.2)$ \\
$\quad$ Cervical rib (Roos 1 or 2) & 3 \\
Fibrous string (Roos 3 or 4) & 18 \\
Scalenus minimus (Roos 5 or 6) & 15 \\
Other & 14 \\
Adhesion neurovascular bundle & $101(77.1)$ \\
Anterior scalene muscle hypertrophy & $69(52.7)$ \\
Middle scalene muscle hypertrophy & $68(51.9)$
\end{tabular}

Values are expressed as $n(\%), n$, or mean \pm standard deviation. ISD, interscalene distance; NVB, neurovascular bundle

Table 3. Clinical outcomes

\begin{tabular}{|c|c|c|c|}
\hline Outcome & Preoperative & Postoperative & $P$ Value \\
\hline \multicolumn{4}{|l|}{ Tenderness } \\
\hline Scalene triangle & $108(80.4)$ & $32(23.9)$ & $<.001$ \\
\hline Fossa scalene & $120(89.9)$ & $26(19.7)$ & $<.001$ \\
\hline $\begin{array}{l}\text { Neurological } \\
\text { symptoms }\end{array}$ & $69(52.1)$ & $18(15.9)$ & $<.001$ \\
\hline Wright test & $91(71.0)$ & $6(4.3)$ & $<.001$ \\
\hline Roos test & $125(95.7)$ & $28(21)$ & $<.001$ \\
\hline Grip power $(\mathrm{kg})$ & $28.4 \pm 13.0$ & $32.0 \pm 13.1$ & .055 \\
\hline \multicolumn{4}{|l|}{ Roos score } \\
\hline Excellent & & $52(39.7)$ & \\
\hline Good & & $53(40.5)$ & \\
\hline Fair & & $18(13.7)$ & \\
\hline Poor & & $8(6.1)$ & \\
\hline DASH score & $40.7 \pm 20.0$ & $15.7 \pm 19.6$ & $<.001$ \\
\hline $\begin{array}{l}\text { DASH score } \\
\quad \text { recovery rate }(\%)^{*}\end{array}$ & $65.5 \pm 33.9$ & & \\
\hline
\end{tabular}

also younger, and a greater number undertook sporting activities and had a lower preoperative DASH score.

No major complications of intimately related structures, including intraoperative neurovascular injury, were found. There was no snapping of the scapula or infection, and no need to repeat the surgery. Complications in this group of patients included 4 cases $(3.0 \%)$ of pneumothorax, l case of incomplete long thoracic nerve paralysis, and 2 cases of incomplete axially nerve paralysis. All complications were resolved within 3 months.

Table 4. Comparison between satisfactory and unsatisfactory

\begin{tabular}{|c|c|c|c|}
\hline Characteristic & Satisfactory & Unsatisfactory & $P$ Value \\
\hline Number & 105 & 26 & \\
\hline Sex (women/men) & $33 / 72$ & $15 / 11$ & .013 \\
\hline Age at surgery (y) & $23.6 \pm 12.2$ & $36.6 \pm 12.1$ & $<.001$ \\
\hline Height $(\mathrm{cm})$ & $166.5 \pm 8.4$ & $165.3 \pm 9.7$ & .524 \\
\hline Weight (kg) & $61.0 \pm 11.4$ & $63.2 \pm 14.4$ & .876 \\
\hline $\begin{array}{l}\text { Body mass } \\
\text { index }\left(\mathrm{kg} / \mathrm{m}^{2}\right)\end{array}$ & $22.0 \pm 3.6$ & $23.1 \pm 7.1$ & .451 \\
\hline $\begin{array}{l}\text { Symptom } \\
\text { duration (mo) }\end{array}$ & $15.8 \pm 29.7$ & $25.3 \pm 31.7$ & .097 \\
\hline Dominant rate $(\%)$ & 76.9 & 71.0 & .672 \\
\hline Sports activity rate $(\%)$ & 61.0 & 11.5 & $<.001$ \\
\hline $\begin{array}{l}\text { Inter Scale } \\
\text { Distance }(\mathrm{mm})\end{array}$ & $5.4 \pm 3.6$ & $5.6 \pm 3.5$ & .741 \\
\hline $\begin{array}{l}\text { NVB (parallel/oblique } \\
\text { /vertical) }\end{array}$ & $23 / 54 / 26$ & $7 / 15 / 4$ & .559 \\
\hline $\begin{array}{l}\text { Preoperative } \\
\text { DASH score }\end{array}$ & $37.6 \pm 18.9$ & $53.4 \pm 19.8$ & $<.001$ \\
\hline $\begin{array}{l}\text { Postoperative } \\
\text { DASH score }\end{array}$ & $7.5 \pm 8.2$ & $49.0 \pm 17.0$ & $<.001$ \\
\hline
\end{tabular}




\section{Discussion}

The current study showed that excellent visualization of the vital structures and surrounding tissue provided satisfactory results after the surgery, with a low percentage of complications. We found favorable outcomes in men, younger patients, those who involved in sports activity, and those who had lower preoperative DASH scores. We believe that this success is achieved because endoscopic-assisted surgery provides visualization of the posterior stump of the first rib and sufficient release and decompression under high magnification without causing neurovascular injury.

Transaxillary first rib resection is a well-established surgical treatment for patients with symptomatic TOS. However, it is also well known that this procedure requires a meticulous technique with special attention to fine details to achieve the best results with the fewest complications. $^{26}$ Because surgery for TOS involves many complex and intimately related structures, theoretical complications are numerous and may be severe. ${ }^{9}$ Therefore, many physicians may hesitate to diagnose and treat TOS.

Several large studies have shown that pneumothorax $(10.1 \%$ to $31.6 \%)$ associated with first rib resection is one of the most common complications. ${ }^{1,13,14,25,27}$ Roos $^{25}$ showed a low complication rate (pneumothorax $10.1 \%$ ), and none serious, in 276 cases. Leffert and Perlmutter ${ }^{1}$ reported an incidence of pneumothorax in 89 of $282(31.6 \%)$.

Recent studies with more refined endoscopes and video cameras have shown improved capability to work at a closer range around the nerve, artery, and vein. ${ }^{17-21}$ These advances provide the surgeon with increased confidence to negotiate the difficulties of the soft tissue cervical bands that interlace these vital structures. We consider that the transaxillary approach and direct visualization of the top surface of the rib are suitable for protection of the subclavian vein and artery during resection of the anterior part of the first rib. Martinez et al. ${ }^{17}$ reported the feasibility of using computer-enhanced instrumentation during transaxillary first rib resection to improve visualization, ensuring patient safety $(2.3 \%$ pulmonary-related problems). Abdellauoi et al. ${ }^{19}$ also showed that endoscopic-assisted transaxillary first rib resection was a safe and effective procedure in the management of thoracic outlet syndrome. Our approach is similar to these techniques; however, those authors focused on vascular decompression and first rib resection. We consider that decompression of the brachial plexus is as important as first rib resection. The endoscope provides excellent visualization of the posterior stump of the first rib, the middle scalene muscle, and the nerve in a deeper and narrower surgical field.
To decompress the brachial plexus completely and permanently, almost the entire first rib must be resected. Mingoli et al. ${ }^{13}$ reported that a strong association was found between long-term outcomes and the presence of a long posterior first rib stump measured on chest $\mathrm{x}$-ray film. Urschel and Razzuk ${ }^{3}$ described that recurrent symptoms after first rib partial resection involved a substantial posterior stump $(>1 \mathrm{~cm})$ of the first rib. Although the transaxillary approach may be more suitable for resection of the first rib from the anterior to middle portion compared with the supraclavicular approach, the risk of the $\mathrm{C} 8$ or $\mathrm{Tl}$ cervical root injury is unavoidable, because the posterior stump of the first rib lies posterior to the root clearly seen at operation. ${ }^{25}$ Therefore, Roos $^{25}$ clearly showed that specially designed rib shears and a root retractor help to remove a posterior first rib with enough safety. We believe that the most important thing for decreasing the risk of neurovascular damage is to maintain excellent visualization during the operation. We also consider that our custom-ordered elevators were useful to help endoscopic visualization. In addition to specially designed instruments, micro-bleeding control and stepby-step decompression of the neurovascular bundle must be performed using a bipolar hemostat. Endoscopic-assisted excellent visualization will help to decrease cervical root injury during posterior rib stump resection.

If peripheral nerve entrapment is the major cause of the pathology of TOS, adequate decompression would be one of the most important procedures in addition to partial resection of the first rib and release of scalene muscles. Surgeons specialized in the peripheral nerves well know that inadequate decompression of the nerve, such as cubital tunnel syndrome ${ }^{28}$ or tarsal tunnel sydrome, ${ }^{29}$ leads to unsuccessful results. From the point of view of neuralgic symptoms, adequate nerve release and decompression for an adhesive or entrapped nerve would be preferably performed under a clear, magnified view for greater safety. Previous articles have suggested that adequate neurolysis for TOS is one of the important procedures for superior outcomes. ${ }^{18,30}$ Endoscopic-assisted surgery helps to achieve meticulous release and decompression during the transaxillary approach.

In addition, the magnified view allows appreciation of minute anatomic detail and is invaluable in the performance of the surgery. We believe that endoscopic evaluation will develop important information related to appropriate diagnosis and surgical criteria. The current study showed tightness between the anterior and middle scalene and a correlation between NVB patterns and ISD: ISD in parallel patterns was wider than that in vertical patterns. Roos ${ }^{31}$ described 9 different clinical types of bands, and 
several experienced surgeons believe these are present. ${ }^{17,27}$ Roos also identified the significance of surgical bands in the pathogenesis of neurovascular compression. ${ }^{24,31}$ Dahlstrom and Olinger ${ }^{32}$ showed that the interscalene base was a mean of $10.7 \mathrm{~mm}$ in a study of 60 cadavers. Other cadaveric studies reported that the average was $1.1,{ }^{33} 1.2$, and $1.5 \mathrm{~cm} .^{34}$ Atasoy ${ }^{35}$ described that the insertions of anterior and middle scalene muscles on the first rib might vary and cause elevation and pressure on the brachial plexus and the subclavian artery from below. Therefore, we consider that the oblique and vertical patterns in endoscopic classification may be a risk factor for failure of conservative treatment of TOS. These previous reports are consistent with the current endoscopic classification. Preoperative evaluation of the NVB patterns and the ISD would help to diagnose the condition and surgical indication. However, the current study showed that there was no significant difference in the clinical score between NVB patterns. This may be a result of several other pathologies of TOS, which have not been clarified, including costoclavicular compression, ${ }^{36-38}$ pectoralis minor syndrome, ${ }^{39,40}$ venous thrombosis (Paget-Schroetter syndrome), ${ }^{41-43}$ general joint laxity, and double crush lesions. ${ }^{44}$ First rib partial resection and nerve decompression would improve some pathologies but perhaps not others. Further studies should be conducted for analyses of pathology.

From the point of view of successful outcomes of endoscopic-assisted transaxillary approach for first rib resection, the current study showed that the satisfactory group involved more younger males who undertook sports activity. Therefore, younger male athletes with TOS may be better candidates for this procedure.

\section{Limitations}

The current study was retrospective, and the follow-up was short. The symptom recurrence rate should be assessed with longer follow-up. The current study did not quantify the feasibility of endoscopic visualization and the amount of first rib resection. We did not compare safety and clinical outcomes in this procedure with the classic one. The diagnosis of TOS is still complicated by alternative disorders with similar presentations. Nerve compression at the cervical spine, shoulder, elbow, and wrist may mask the presentation of TOS.

\section{Conclusions}

An endoscopic-assisted transaxillary approach for first rib resection in TOS provides excellent magnified visualization, safely allowing sufficient decompression of the neurovascular bundle and satisfactory surgical outcomes. Younger male athletes with TOS may be better candidates for this procedure.

\section{References}

1. Leffert RD, Perlmutter GS. Thoracic outlet syndrome. Results of 282 transaxillary first rib resections. Clin Orthop Relat Res 1999:66-79.

2. Roos DB, Owens JC. Thoracic outlet syndrome. Arch Surg 1966;93:71-74.

3. Urschel HC Jr, Razzuk MA. Neurovascular compression in the thoracic outlet: changing management over 50 years. Ann Surg 1998;228:609-617.

4. Ide J, Kataoka Y, Yamaga M, Kitamura T, Takagi K. Compression and stretching of the brachial plexus in thoracic outlet syndrome: Correlation between neuroradiographic findings and symptoms and signs produced by provocation manoeuvres. J Hand Surg Br 2003;28: 218-223.

5. Rosenbaum AJ, Vanderzanden J, Morse AS, Uhl RL. Injuries complicating musical practice and performance: the hand surgeon's approach to the musician-patient. J Hand Surg Am 2012;37:1269-1272.

6. Bottros MM, AuBuchon JD, McLaughlin LN, Altchek DW, Illig KA, Thompson RW. Exercise-enhanced, ultrasoundguided anterior scalene muscle/pectoralis minor muscle blocks can facilitate the diagnosis of neurogenic thoracic outlet syndrome in the high-performance overhead athlete. Am J Sports Med 2017;45:189-194.

7. Rayan GM. Thoracic outlet syndrome. J Shoulder Elbow Surg 1998;7:440-451.

8. Roos DB. Thoracic outlet syndrome is underdiagnosed. Muscle Nerve 1999;22:126-129.

9. Kuhn JE, Lebus VG, Bible JE. Thoracic outlet syndrome. J Am Acad Orthop Surg 2015;23:222-232.

10. Derkash RS, Goldberg VM, Mendelson H, Mevicker R. The results of first rib resection in thoracic outlet syndrome. Orthopedics 1981;4:1025-1029.

11. Roos DB. Transaxillary approach for first rib resection to relieve thoracic outlet syndrome. Ann Surg 1966;163: 354-358.

12. Atasoy E. Combined surgical treatment of thoracic outlet syndrome: Transaxillary first rib resection and transcervical scalenectomy. Hand Clin 2004;20:71-82. vii.

13. Mingoli A, Feldhaus RJ, Farina C, et al. Long-term outcome after transaxillary approach for thoracic outlet syndrome. Surgery 1995;1 18:840-844.

14. Karamustafaoglu YA, Yoruk Y, Tarladacalisir T, Kuzucuoglu M. Transaxillary approach for thoracic outlet syndrome: Results of surgery. Thorac Cardiovasc Surg $2011 ; 59: 349-352$.

15. Hempel GK, Shutze WP, Anderson JF, Bukhari HI. 770 consecutive supraclavicular first rib resections for thoracic outlet syndrome. Ann Vasc Surg 1996;10:456-463.

16. Archie MM, Rollo JC, Gelabert HA. Surgical missteps in the management of venous thoracic outlet syndrome which lead to reoperation. Ann Vasc Surg 2018;49:261-267.

17. Martinez BD, Wiegand CS, Evans P, Gerhardinger A, Mendez J. Computer-assisted instrumentation during endoscopic transaxillary first rib resection for thoracic outlet syndrome: A safe alternate approach. Vascular 2005; 13:327-335.

18. Lafosse T, Le Hanneur M, Lafosse L. All-endoscopic brachial plexus complete neurolysis for idiopathic 
neurogenic thoracic outlet syndrome: A prospective case series. Arthroscopy 2017;33:1449-1457.

19. Abdellaoui A, Atwan M, Reid F, Wilson P. Endoscopic assisted transaxillary first rib resection. Interact Cardiovasc Thorac Surg 2007;6:644-646.

20. Chan YC, Gelabert HA. High-definition video-assisted transaxillary first rib resection for thoracic outlet syndrome. J Vasc Surg 2013;57:1155-1158.

21. George RS, Milton R, Chaudhuri N, Kefaloyannis E, Papagiannopoulos K. Totally endoscopic (VATS) first rib resection for thoracic outlet syndrome. Ann Thorac Surg 2017; 103:241-245.

22. Peek J, Vos CG, Unlu C, van de Pavoordt H, van den Akker PJ, de Vries JPM. Outcome of surgical treatment for thoracic outlet syndrome: Systematic review and metaanalysis. Ann Vasc Surg 2017;40:303-326.

23. Irving S, Wright MC. The neurovascular syndrome produced by hyperabduction of the arm. Am Heart J 1945;29: $1-19$.

24. Roos DB. Congenital anomalies associated with thoracic outlet syndrome. Anatomy, symptoms, diagnosis, and treatment. Am J Surg 1976;132:771-778.

25. Roos DB. Experience with first rib resection for thoracic outlet syndrome. Ann Surg 1971;173:429-442.

26. Roos DB. Essentials and safeguards of surgery for thoracic outlet syndrome. Angiology 1981;32:187-193.

27. Wood VE, Twito R, Verska JM. Thoracic outlet syndrome. The results of first rib resection in 100 patients. Orthop Clin North Am 1988;19:131-146.

28. Kleinman WB. Revision ulnar neuroplasty. Hand Clin 1994;10:461-477.

29. Yalcinkaya M, Ozer UE, Yalcin MB, Bagatur AE. Neurolysis for failed tarsal tunnel surgery. J Foot Ankle Surg 2014;53:794-798.

30. Terzis JK, Kokkalis ZT. Supraclavicular approach for thoracic outlet syndrome. Hand (N Y) 2010;5:326-337.

31. Roos DB. Pathophysiology of congenital anomalies in thoracic outlet syndrome. Acta Chir Belg 1980;79:353-361.
32. Dahlstrom KA, Olinger AB. Descriptive anatomy of the interscalene triangle and the costoclavicular space and their relationship to thoracic outlet syndrome: A study of 60 cadavers. J Manipulative Physiol Ther 2012;35:396-401.

33. Daseler EH, Anson BJ. Surgical anatomy of the subclavian artery and its branches. Surg Gynecol Obstet 1959;108:149-174.

34. Kaplan T, Comert A, Esmer AF, et al. The importance of costoclavicular space on possible compression of the subclavian artery in the thoracic outlet region: A radioanatomical study. Interact Cardiovasc Thorac Surg 2018;27: 561-565.

35. Atasoy E. Thoracic outlet syndrome: Anatomy. Hand Clin 2004;20:7-14. V.

36. Pomerantz RB. Functional subclavian arterial murmur; possible relation to scalenus anticus syndrome, costoclavicular compression, or the neurovascular syndrome of Wright. Ann Surg 1948;127:688-695.

37. Falconer MA. The costoclavicular syndrome. $\mathrm{Br}$ Med $J$ 1947;2:69.

38. Falconer MA, Li FW. Resection of the first rib in costoclavicular compression of the brachial plexus. Lancet 1962;1:59-63.

39. Lord JW Jr, Stone PW. Pectoralis minor tenotomy and anterior scalenotomy with special reference to the hyperabduction syndrome and effort thrombosis of the subclavian vein. Circulation 1956;13:537-542.

40. McIntyre DI. Subcoracoid neurovascular entrapment. Clin Orthop Relat Res 1975:27-30.

41. Paget J. Clinical Lectures and Essays. London: Longmans Green, 1875.

42. Wilson MJ, Silverstein ME. Paget-Schroetter syndrome; report of a case of one of the more unusual neurovascular syndromes of the upper limb. AMA Arch Intern Med 1951;88:507-511.

43. Illig KA, Doyle AJ. A comprehensive review of PagetSchroetter syndrome. J Vasc Surg 2010;51:1538-1547.

44. Upton AR, McComas AJ. The double crush in nerve entrapment syndromes. Lancet 1973;2:359-362. 